\title{
Dietary patterns and whole grain cereals in the Scandinavian countries - differences and similarities. The HELGA project
}

\author{
Dagrun Engeset ${ }^{1, *}$, Dag Hofoss ${ }^{1,2}$, Lena M Nilsson ${ }^{3}$, Anja Olsen $^{4}$, Anne Tiønneland ${ }^{4}$ and \\ Guri Skeie \\ 'Department of Community Medicine, UiT The Arctic University of Norway, N-9037 Tromsø, Norway: ${ }^{2}$ Department \\ of Nursing Science, Faculty of Medicine, University of Oslo, Oslo, Norway: ${ }^{3}$ Department of Public Health and \\ Clinical Medicine, Nutritional Research, Umeå University, Umeå, Sweden: ${ }^{4}$ Diet, Genes and Environment, The \\ Danish Cancer Society Research Center, Copenhagen, Denmark
}

Submitted 15 November 2013: Final revision received 1 April 2014: Accepted 30 April 2014: First published online 5 June 2014

\begin{abstract}
Objective: To identify dietary patterns with whole grains as a main focus to see if there is a similar whole grain pattern in the three Scandinavian countries; Denmark, Sweden and Norway. Another objective is to see if items suggested for a Nordic Food Index will form a typical Nordic pattern when using factor analysis. Setting: The HELGA study population is based on samples of existing cohorts: the Norwegian Women and Cancer Study, the Swedish Västerbotten cohort and the Danish Diet, Cancer and Health study. The HELGA study aims to generate knowledge about the health effects of whole grain foods.

Subjects: The study included a total of 119913 participants.

Design: The associations among food variables from FFQ were investigated by principal component analysis. Only food groups common for all three cohorts were included. High factor loading of a food item shows high correlation of the item to the specific diet pattern.

Results: The main whole grain for Denmark and Sweden was rye, while Norway had highest consumption of wheat. Three similar patterns were found: a cereal pattern, a meat pattern and a bread pattern. However, even if the patterns look similar, the food items belonging to the patterns differ between countries.

Conclusions: High loadings on breakfast cereals and whole grain oat were common in the cereal patterns for all three countries. Thus, the cereal pattern may be considered a common Scandinavian whole grain pattern. Food items belonging to a Nordic Food Index were distributed between different patterns.
\end{abstract}

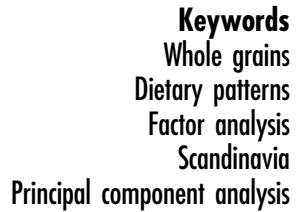

Keywords

Dietary patterns Factor analysis

Scandinavia

Principal component analysis
In recent years a trend within nutritional epidemiology has been to assess overall dietary quality; however, no overall standard on how to best capture the whole diet has been set ${ }^{(1-3)}$.

Several computer-driven (a posteriori) studies from the Scandinavian countries have identified dietary patterns by use of factor or cluster analysis, and some of them have reported country-specific or traditional patterns ${ }^{(4-8)}$. However, to our knowledge no studies have looked at patterns in the Scandinavian countries in a combined way. In a study of the diversity of dietary patterns in the European Prospective Investigation into Cancer and Nutrition (EPIC), mean dietary intake from $24 \mathrm{~h}$ dietary recalls from each participating centre was compared with an overall EPIC mean and showed that the diet was relatively similar in the Scandinavian countries, but the proportions of what was consumed varied across countries and indicated country-specific dietary patterns ${ }^{(9)}$.

Among theoretically (a priori) defined patterns, the Mediterranean diet has been associated with positive health outcomes in many studies ${ }^{(10-14)}$. Similarly, a Nordic Food Index has been suggested for the Nordic countries. In recent studies, a Nordic diet including fish, cabbages, whole grain rye, whole grain oat, apples/pears and root vegetables has also been related to a range of beneficial health effects ${ }^{(15-18)}$.

In the HELGA project, a joint project including parts of three Scandinavian countries, the aim is to establish a Nordic comprehensive foundation for whole grain research and to generate knowledge about the health effects of whole grain foods. A high intake of whole grains has been associated with a reduced risk of several 
lifestyle-related diseases ${ }^{(19,20)}$, and the whole grain consumption in Scandinavia is traditionally higher than in many European countries and the $\mathrm{USA}^{(21)}$.

There are also common whole grain recommendations for Scandinavia ${ }^{(22-24)}$, but the type of grain dominating the whole grain intake differs between countries ${ }^{(21)}$.

The aim of the present study is to identify dietary patterns for the HELGA cohort by use of principal component analysis (PCA) to see if we find a common whole grain pattern for the three countries and to see if the items suggested for a Nordic Food Index will form a typical Nordic pattern or will be distributed on several different patterns.

\section{Method}

\section{Study population}

The HELGA study population consists of sub-samples of existing cohorts from the three Scandinavian countries: the Norwegian Women and Cancer Study, the Västerbotten Intervention Programme and the Danish Diet, Cancer and Health study. All three cohorts are part of the EPIC study. The participants were recruited from the general population, but the Norwegian study only includes women. At baseline (1992-1998), the participants filled in a questionnaire regarding their habitual food intake and lifestyle. The full HELGA cohort includes a total of 120016 participants.

The study was conducted according to the guidelines laid down in the Declaration of Helsinki. All participants gave written informed consent, and the study was approved by the local ethical committees of the participating countries.

\section{Diet questionnaires}

The HELGA cohort collected dietary information through different validated $\mathrm{FFQ}^{(25-28)}$. Whole grain variables from the FFQ were reclassified to distinguish between the different types of whole grains (wheat, rye, oat, others), and the reclassified whole grain variables were used together with other relevant food variables in the present study.

Food intake from the dietary questionnaires was translated into main food groups and subgroups, using the food classification system developed in EPIC ${ }^{(29)}$. Due to missing information on diet from some participants, the current study includes a total of 119913 participants; only foods/ food groups common for all three cohorts are included.

The particular food groups included in the analyses are: potatoes, vegetables, fruit, nuts/nut-spread and seeds, milk, yoghurt/thick fermented milk, cheese, dairy creams, pasta, rice, white bread, non-white bread, crisp bread/ rusks, breakfast cereals, salty biscuits/aperitif biscuits/ crackers, red meat, poultry, processed meat, fish, crustaceans/molluscs, fish products/fish in crumbs, egg and egg products, vegetable oils, butter, margarine, sugar/honey/ jam/syrup, chocolate/candy bars/paste/confetti, ice cream/ water/ice, cakes and biscuits, fruit and vegetable juices, carbonated/soft/isotonic drinks and diluted syrups, coffee/tea/herbal tea, water, alcoholic beverages, condiments and sauces, whole wheat cereal, whole rye cereal, whole oat cereal, other whole grain cereals. The whole grain cereals may be referred to as only oat, wheat or rye later in the present paper.

Other food groups were not included into the analyses due to inhomogeneous quality in questionnaire information between the countries and/or very low intakes.

\section{The Nordic Food Index}

For simplicity, and to reduce the number of variables, no subgroups of fruit and vegetables were included. Therefore the food groups used in the present study do not give detailed information about different types of fruits and vegetables, like apples, pears, cabbages and root vegetables as suggested parts of a Nordic Food Index. However, all four items were included in the food groups 'fruit' and 'vegetables'; thus these food groups were used together with the food groups 'fish', 'crustaceans/ molluscs', fish products/fish in crumbs', 'whole rye cereal' and 'whole oat cereal' to examine the Nordic diet items in the patterns found.

\section{Statistical methods}

The associations between the variables were investigated by using PCA (IBM SPSS Statistics 19), the most commonly used approach in factor analysis of dietary data $^{(30)}$. The factors were constructed by orthogonal varimax transformation to maintain uncorrelated factors and greater interpretability. Two criteria were used in order to choose the number of factors: the eigenvalue criterion (eigenvalue $>1$ ) and the scree plot. In addition we looked at the interpretability of the factors and how much detail they gave about whole grains since this was part of the aim.

Food items with positive loadings contribute to a dietary pattern; food items with negative loadings are inversely associated with a dietary pattern. Only items with absolute factor loadings of 0.3 or higher were considered in the interpretation of the factors. The higher the factor loading of a food item, the higher correlation of that item to that specific diet factor/pattern.

Analyses were conducted for the total cohort and separately for the different countries. Separate analyses were also performed for men and women.

The factors found in the total cohort were divided into quartiles and examined using the $\chi^{2}$ test for categorical variables to look at the distribution of persons belonging to the different countries and of different genders.

To test the robustness of the patterns the data were divided randomly into two arbitrary parts and the analysis was repeated as in the total set. This procedure was done for the total cohort and for the three countries separately. 


\section{Results}

Mean age for the Danish participants was approximately 8-10 years higher than for the Norwegian and Swedish participants, and they also had a lower mean intake of total whole grains. Both Denmark and Sweden had rye as their main whole grain item, while Norway had highest consumption of wheat (Table 1).

The Danish participants had the highest consumption of fruit and vegetables; however, they also had the highest consumption of alcohol and red meat, and they had the highest BMI (mean $26 \mathrm{~kg} / \mathrm{m}^{2}$ ) compared with the other countries (Table 1)

Sweden had the lowest consumption of non-white bread, and had a substantially higher consumption of crisp bread and breakfast cereals than both Norway and Denmark (Table 1).

\section{Patterns from principal component analysis: total cobort}

The eigenvalue criterion alone indicated that there were ten important factors for the total cohort (Norway, Sweden and Denmark together). However, the scree plot indicated that only six factors were of importance. When studying the factors, all six factors were interpretable but the strong overlapping of the factors suggested that a three- or fourfactor solution would be more meaningful. The three-factor solution revealed one fish factor (fish, fish products, vegetables and non-white bread), one meat factor (red meat, poultry, coffee, water and alcohol) and one cereal factor (white bread, crisp bread, breakfast cereals and cakes). We decided, however, to go for the four-factor solution since this gave more detailed information about whole grains (Table 2).

The patterns in the four-factor solution were named 'meat and beverages', 'bread and potatoes', 'fish and nonwhite bread' and 'cereals and vegetables', based on the food items with the highest loadings in each pattern or the food items most characteristic for the pattern (an item may give name to a pattern even though other items have higher loadings because these items are seen to supplement the naming item, e.g. 'bread pattern' where margarine had higher loading but is associated with buttered sandwiches). The 'cereals and vegetables' pattern had highest loading on oat, but had quite high loadings on rye and other grains as well. The 'bread and potatoes' pattern had the highest loadings on rye and other whole grains, and the 'fish and non-white bread' had the highest loading on wheat. The 'meat' pattern and the 'fish' pattern remained the same as in the three-factor solution. The four factors explained $33 \%$ of the variation (Table 2).

The 'meat and beverages' pattern was completely dominated by the Danes in the highest quartiles, while they were almost absent in the lowest ones. There was also a higher percentage of male participants in the

Table 1 Characteristics of the total cohort and by country. The HELGA project

\begin{tabular}{|c|c|c|c|c|}
\hline & $\begin{array}{l}\text { Total cohort } \\
(n \text { 119 913) }\end{array}$ & $\begin{array}{c}\text { Norway } \\
\text { (n } 37 \text { 190) }\end{array}$ & $\begin{array}{l}\text { Sweden } \\
(n \text { 25 725) }\end{array}$ & $\begin{array}{r}\text { Denmark } \\
\text { (n } 56 \text { 998) }\end{array}$ \\
\hline Age at enrolment (years), mean & $51 \cdot 8$ & $48 \cdot 2$ & $46 \cdot 0$ & $56 \cdot 7$ \\
\hline \multicolumn{5}{|l|}{ Gender (\%) } \\
\hline Male & 33.0 & 0.0 & 48.3 & $47 \cdot 6$ \\
\hline Female & $67 \cdot 0$ & $100 \cdot 0$ & 51.7 & $52 \cdot 4$ \\
\hline Total whole grains $(\mathrm{g} / \mathrm{d})$, mean & $52 \cdot 1$ & $60 \cdot 1$ & 62.9 & $42 \cdot 0$ \\
\hline Rye & $25 \cdot 4$ & 11.8 & 38.3 & 28.5 \\
\hline Wheat & $17 \cdot 7$ & $42 \cdot 1$ & 11.5 & 4.6 \\
\hline Oat & $7 \cdot 1$ & $5 \cdot 0$ & 8.4 & $7 \cdot 9$ \\
\hline Alcohol consumption (g/d), mean & 11.3 & $2 \cdot 8$ & 3.2 & 20.5 \\
\hline Vegetable consumption $(\mathrm{g} / \mathrm{d})$, mean & 148.4 & 141.9 & $93 \cdot 3$ & 177.5 \\
\hline Fruit consumption $(\mathrm{g} / \mathrm{d})$, mean & $169 \cdot 0$ & $157 \cdot 3$ & $163 \cdot 0$ & $179 \cdot 3$ \\
\hline Bread non-white $(\mathrm{g} / \mathrm{d})$, mean & 100.5 & $121 \cdot 7$ & $28 \cdot 3$ & $119 \cdot 2$ \\
\hline Bread white g/d (mean) & 18.4 & $5 \cdot 0$ & $28 \cdot 1$ & $22 \cdot 8$ \\
\hline Crisp bread $(\mathrm{g} / \mathrm{d})$, mean & $14 \cdot 8$ & 8.5 & 45.0 & $5 \cdot 3$ \\
\hline Breakfast cereals $(\mathrm{g} / \mathrm{d})$, mean & $20 \cdot 8$ & $13 \cdot 1$ & $51 \cdot 1$ & $12 \cdot 2$ \\
\hline Processed meat $(\mathrm{g} / \mathrm{d})$, mean & 34.3 & 39.4 & $36 \cdot 8$ & 29.9 \\
\hline Red meat consumption $(\mathrm{g} / \mathrm{d})$, mean & $47 \cdot 0$ & $22 \cdot 3$ & $16 \cdot 6$ & 76.9 \\
\hline Fish consumption $(g / d)$, mean & 39.2 & 73.0 & 6.6 & 31.9 \\
\hline BMI $\left(\mathrm{kg} / \mathrm{m}^{2}\right)$, mean & $25 \cdot 3$ & $24 \cdot 4$ & $25 \cdot 0$ & $26 \cdot 1$ \\
\hline \multicolumn{5}{|l|}{ Smoking (\%) } \\
\hline Never & 39.6 & 33.5 & 58.7 & 34.9 \\
\hline Former & $27 \cdot 8$ & $29 \cdot 3$ & 19.9 & 30.4 \\
\hline Current & $30 \cdot 4$ & 31.5 & $20 \cdot 0$ & $34 \cdot 4$ \\
\hline Unknown & $2 \cdot 2$ & 5.7 & 1.3 & 0.3 \\
\hline \multicolumn{5}{|l|}{ Education $(\%)^{\star}$} \\
\hline Primary school or less & $29 \cdot 1$ & 23.4 & 28.4 & 33.0 \\
\hline Technical/professional school & 33.9 & $35 \cdot 8$ & 21.7 & 38.2 \\
\hline Secondary school & 19.5 & $28 \cdot 4$ & $28 \cdot 1$ & $9 \cdot 8$ \\
\hline Longer education/university & $17 \cdot 3$ & $12 \cdot 3$ & $21 \cdot 1$ & $18 \cdot 7$ \\
\hline
\end{tabular}

${ }^{*}$ Do not reach $100 \%$ due to missing values. 
Table 2 Factor loadings for the four-factor solution (dietary patterns) patterns in the total cohort. The HELGA project

\begin{tabular}{|c|c|c|c|c|}
\hline Food variable & $\begin{array}{l}\text { 'Meat and } \\
\text { beverages' }\end{array}$ & $\begin{array}{l}\text { 'Bread and } \\
\text { potatoes' }\end{array}$ & $\begin{array}{c}\text { 'Fish and } \\
\text { non-white bread' }\end{array}$ & $\begin{array}{l}\text { 'Cereals and } \\
\text { vegetables' }\end{array}$ \\
\hline Potatoes & & 0.516 & & \\
\hline Vegetables & & & 0.398 & 0.508 \\
\hline Fruit & & & & 0.474 \\
\hline \multicolumn{5}{|l|}{ Nuts and seeds } \\
\hline \multicolumn{5}{|l|}{ Milk } \\
\hline Yoghurt & & & & 0.473 \\
\hline Cheese & & & 0.328 & \\
\hline Dairy creams & & 0.323 & & \\
\hline Pasta & & & & 0.370 \\
\hline Rice & & & & 0.374 \\
\hline White bread & & 0.514 & & \\
\hline Non-white bread & & & 0.636 & \\
\hline Crisp bread & -0.356 & 0.581 & -0.387 & \\
\hline Breakfast cereals & -0.307 & & & 0.564 \\
\hline \multicolumn{5}{|l|}{ Salty biscuits } \\
\hline Red meat & 0.776 & & & \\
\hline Poultry & 0.389 & & & 0.303 \\
\hline Processed meat & & 0.558 & 0.350 & \\
\hline Fish & & & 0.660 & \\
\hline Crustaceans, molluscs & & & 0.389 & \\
\hline Fish products & & & 0.453 & \\
\hline Egg & 0.511 & & 0.355 & \\
\hline Vegetable oils & & & & 0.422 \\
\hline \multicolumn{5}{|l|}{ Butter } \\
\hline Margarine & & 0.715 & & \\
\hline Sugar, honey, jam & & 0.320 & & \\
\hline \multicolumn{5}{|l|}{ Chocolate } \\
\hline Ice cream & 0.329 & & & \\
\hline Cakes and biscuits & -0.385 & 0.455 & & \\
\hline \multicolumn{5}{|l|}{ Fruit and vegetable juices } \\
\hline \multicolumn{5}{|c|}{ Carbonated drinks, soft drinks } \\
\hline Coffee, tea, herbal tea & 0.659 & & & \\
\hline Water & 0.669 & & & \\
\hline Alcoholic beverages & 0.519 & & & \\
\hline Condiments and sauces & 0.415 & & 0.329 & \\
\hline Whole wheat cereal & -0.657 & & 0.543 & \\
\hline Whole rye cereal & & 0.556 & & 0.322 \\
\hline Whole oat cereal & & & & 0.626 \\
\hline Whole grain cereal, other & -0.315 & 0.564 & & 0.343 \\
\hline Variance explained (\%) & $9 \cdot 8$ & $8 \cdot 8$ & $7 \cdot 7$ & $6 \cdot 7$ \\
\hline
\end{tabular}

${ }^{*}$ Factor loadings below \pm 0.30 are not listed in the table.

highest quartile. The 'bread and potatoes' pattern had a higher percentage of the Swedish participants in the highest quartile, and more than $50 \%$ of male participants were found here. The 'fish and non-white bread' pattern was highly dominated by Norwegians in the highest quartile; however, males and females were more evenly distributed across the quartiles. While a slightly higher percentage of the Danes and Swedes were found in the highest quartile of the 'cereals and vegetables' pattern, only $9 \%$ of the Norwegian participants were found here. Again, males and females were evenly distributed across the quartiles (Table 3).

As for the items indicating the Nordic Food Index, they were distributed between three patterns: 'bread and potatoes' (with whole grain rye), 'fish and non-white bread' (with vegetables and fish) and 'cereals and vegetable' (with fruit, vegetables and whole grain oat).

When looking separately at the males, three distinct factors appeared when taking whole grains into consideration (see online supplementary material, Supplemental Table 1). The first factor was a 'meat and fish' pattern scoring high on red meat, poultry, fish, egg products and vegetables. It also had a high score on nonwhite bread; however, it did not score high on any of the whole grain variables. The second factor made a 'bread' pattern with white bread, crisp bread, processed meat, margarine and cakes. It had the highest score on rye and other grains. The third factor was named 'cereal' pattern because of its high score on breakfast cereals and all the whole grain items, especially wheat and oat.

For women in the total cohort we saw three patterns as well (Supplemental Table 1); however, this time there were a 'meat and beverages' pattern, a 'cereal' pattern and a 'fish and non-white bread' pattern. The first pattern scored high on red meat and egg, as well as most of the drinks. The second pattern scored high on crisp bread, breakfast cereals and on all of the whole grain items except wheat. The last pattern had a high score on non- 
Table 3 Distribution of countries and genders in the dietary patterns of the total cohort. The HELGA project

\begin{tabular}{|c|c|c|c|c|c|c|c|c|c|c|c|c|c|c|c|c|}
\hline & \multicolumn{4}{|c|}{ 'Meat and beverages' } & \multicolumn{4}{|c|}{ 'Bread and potatoes' } & \multicolumn{4}{|c|}{ 'Fish and non-white bread' } & \multicolumn{4}{|c|}{ 'Cereals and vegetables' } \\
\hline & Q1 & Q2 & Q3 & Q4 & Q1 & Q2 & Q3 & Q4 & Q1 & Q2 & Q3 & Q4 & Q1 & Q2 & Q3 & Q4 \\
\hline \multicolumn{17}{|c|}{ Countries (\%) } \\
\hline Norway & $57 \cdot 0$ & $40 \cdot 0$ & 3.0 & 0.0 & $35 \cdot 0$ & 34.6 & $24 \cdot 0$ & 6.5 & $3 \cdot 1$ & $12 \cdot 7$ & $31 \cdot 1$ & 53.1 & $36 \cdot 2$ & $32 \cdot 7$ & $21 \cdot 8$ & $9 \cdot 3$ \\
\hline Sweden & $34 \cdot 1$ & $58 \cdot 0$ & $7 \cdot 8$ & 0.1 & $6 \cdot 3$ & $12 \cdot 2$ & $23 \cdot 2$ & $58 \cdot 3$ & $75 \cdot 5$ & 17.9 & 4.9 & 1.7 & $14 \cdot 2$ & $21 \cdot 6$ & $27 \cdot 8$ & $36 \cdot 4$ \\
\hline Denmark & 0.0 & 0.3 & $47 \cdot 1$ & $52 \cdot 6$ & $26 \cdot 9$ & 24.5 & $26 \cdot 5$ & $22 \cdot 0$ & $16 \cdot 5$ & $36 \cdot 2$ & $30 \cdot 1$ & $17 \cdot 1$ & 22.5 & 21.5 & $25 \cdot 8$ & $30 \cdot 1$ \\
\hline \multicolumn{17}{|l|}{ Gender (\%) } \\
\hline Men & 11.4 & $16 \cdot 9$ & $26 \cdot 7$ & $45 \cdot 1$ & $6 \cdot 7$ & $14 \cdot 3$ & $27 \cdot 3$ & $51 \cdot 6$ & $29 \cdot 8$ & $26 \cdot 7$ & $25 \cdot 8$ & $17 \cdot 8$ & $26 \cdot 4$ & $20 \cdot 9$ & $23 \cdot 6$ & $29 \cdot 1$ \\
\hline Women & $31 \cdot 7$ & $29 \cdot 0$ & $24 \cdot 2$ & $15 \cdot 1$ & $34 \cdot 0$ & $30 \cdot 3$ & $23 \cdot 9$ & 11.9 & $22 \cdot 6$ & $24 \cdot 2$ & $24 \cdot 6$ & $28 \cdot 6$ & $24 \cdot 3$ & $27 \cdot 0$ & $25 \cdot 7$ & 23.0 \\
\hline
\end{tabular}

white bread, fish and fish products, and scored highest on wheat. This pattern was dominated by Norwegians (data not shown).

\section{Patterns from principal component analysis: country specific}

When studying the factors for the different countries, a three- or four-factor solution was most meaningful for all three countries. A four-factor solution gave a little more detailed information that was lost with a three-factor solution. However, as the whole grain factors remained unchanged whether three or four factors were included, and to ensure comparability between countries, we went for the three-factor solution (Table 4).

\section{Norway}

The three-factor solution (Table 4, Fig. 1(c)) revealed what we may call a 'cereal' pattern which includes breakfast cereals, rye, oat and other whole grain items. The second pattern was a 'bread' pattern, with non-white bread, jam, margarine and whole-grain wheat, and the last pattern was a 'meat and fish' pattern including items like fish and fish products, meat and meat products, vegetables, condiments and sauces, and water. The scores were only moderately high for meat and fish items. The three factors explained $25 \%$ of the variation.

For Norway, items included in the Nordic Food Index were divided between two patterns: the 'cereal' pattern (fruit, whole grain rye and whole grain oat) and the "meat and fish' pattern (fish, fish products and vegetables).

\section{Sweden}

We found the same type of pattern in Sweden as in Norway, but they differed from one another in content. The first pattern, a 'bread' pattern, included white bread, crisp bread, processed meat, margarine, jam, cakes, whole grain rye and other whole grains. The second pattern was named 'meat and fish' and scored high on red meat as well as pasta and rice, but did not score high on fish, and only moderately high on fish products. The third pattern, named 'cereals and non-white bread', scored high on nonwhite bread and breakfast cereals, as well as on all the main whole grain cereals (Table 4). The three factors explained $29 \%$ of the variation.
Sweden was quite comparable to Norway concerning Nordic Food Index items, with fruit, vegetables, whole grain rye and whole grain oat in the 'cereal' pattern, and vegetables, crustaceans and fish products in the 'meat and fish' pattern.

In gender-specific analyses, we found the same three patterns for both men (Fig. 2(a), Supplemental Table 2) and women (Fig. 1(a), Supplemental Table 3); one 'cereal' pattern with non-white bread and breakfast cereals, one 'meat and fish' pattern with meat and fish products, and one 'bread' pattern with white bread, crisp bread and sweet products. However, the 'meat and fish' patterns and the 'bread' patterns did not appear in the same order. The three factors explained $29 \%$ of the variation for men and $27 \%$ for women.

\section{Denmark}

The first pattern for Denmark was a 'meat and fish' pattern with moderately high scores on meat and fish, and with quite high scores on pasta, rice and vegetables. It also had a high score on other whole grains. The second pattern was a 'cereals' pattern that scored high on breakfast cereals, wheat and oat. A 'bread' pattern was seen for Denmark as well, including non-white bread, processed meat, margarine and rye (Table 4 ). The three factors explained $24 \%$ of the variation.

Unlike Sweden and Norway, the Nordic Food Index items were divided on all three patterns; the 'cereals' pattern (fruit, vegetables and whole grain oat), the 'bread' pattern (whole grain rye) and the 'meat and fish' pattern (vegetables and fish/fish products).

When divided into men and women, Danish men had a 'meat and fish' pattern, a 'cereals' pattern and a 'bread' pattern (Fig. 2(b), Supplemental Table 2), as seen for total men. The 'cereals' pattern had high scores on breakfast cereals and wheat and oat. The 'bread' pattern had high scores on nonwhite bread and rye. The 'meat and fish pattern' had highest scores on rice and other grains and moderately high scores on the different meat and fish items.

Danish females (Fig. 1(b), Supplemental Table 3) had a 'poultry and fish' pattern with highest scores on vegetables, rice and other whole grains, and moderately high scores on poultry and fish. The 'cereals' pattern was similar to the men's 'cereals' pattern with breakfast cereals, wheat and oat as main items. The 'bread' pattern seen for Danish women was similar to the men's, with non-white 
Table 4 Factor loadings for the patterns found in Norway, Sweden and Denmark for the total cohort*. The HELGA project

\begin{tabular}{|c|c|c|c|c|c|c|c|c|c|}
\hline \multirow[b]{2}{*}{ Food variable } & \multicolumn{3}{|c|}{ Norway } & \multicolumn{3}{|c|}{ Sweden } & \multicolumn{3}{|c|}{ Denmark } \\
\hline & 'Cereals' & 'Bread' & 'Meat and fish' & 'Bread' & 'Meat and fish' & 'Cereals and non-white bread' & 'Meat and fish' & 'Cereals' & 'Bread' \\
\hline Potatoes & & 0.381 & & 0.413 & & & & & 0.398 \\
\hline Vegetables & & & 0.502 & & 0.427 & 0.402 & 0.548 & 0.358 & \\
\hline Fruit & 0.335 & & & & & 0.406 & & 0.358 & \\
\hline Nuts and seeds & & & & & 0.360 & -0.347 & & & \\
\hline Milk & & & & 0.475 & & & & & \\
\hline Yoghurt & 0.379 & & & & & 0.340 & & 0.378 & \\
\hline Cheese & & 0.408 & & 0.343 & & & & & 0.346 \\
\hline Dairy creams & & & 0.357 & & & & 0.460 & & \\
\hline Pasta & & & & & 0.561 & & 0.524 & & \\
\hline Rice & & & & & 0.586 & & 0.682 & & \\
\hline White bread & & & & 0.444 & & & & -0.441 & \\
\hline Non-white bread & & 0.825 & & & & 0.648 & & & 0.692 \\
\hline Crisp bread & 0.377 & & & 0.733 & & & & & \\
\hline Breakfast cereals & 0.880 & & & & & 0.618 & & 0.648 & \\
\hline Salty biscuits & & & & & 0.350 & -0.343 & & & \\
\hline Red meat & & & 0.468 & 0.423 & 0.618 & & 0.392 & -0.447 & 0.308 \\
\hline Poultry & & & 0.355 & & 0.578 & & 0.506 & & \\
\hline Processed meat & & 0.379 & 0.333 & 0.553 & 0.360 & & & -0.478 & 0.506 \\
\hline Fish & & & 0.550 & & & & 0.532 & & \\
\hline Crustaceans, molluscs & & & 0.407 & & 0.413 & & 0.320 & & \\
\hline Fish products & & & 0.349 & & 0.340 & & 0.308 & & \\
\hline Egg & & & 0.337 & 0.458 & 0.526 & & & & \\
\hline Vegetable oils & & & 0.652 & & 0.366 & & 0.491 & & \\
\hline Butter & & & & & & & & & \\
\hline Margarine & & 0.600 & & 0.640 & & & & -0.309 & 0.624 \\
\hline Sugar, honey, jam & & 0.459 & & 0.463 & & & & & 0.386 \\
\hline $\begin{array}{l}\text { Chocolate } \\
\text { Ice cream }\end{array}$ & & & & & & & & & \\
\hline Cakes and biscuits & & & & 0.503 & & & & & 0.312 \\
\hline Fruit and vegetable juices & & & & & & & & & \\
\hline Carbonated drinks, soft drinks & & & & 0.323 & & & & & \\
\hline Coffee, tea, herbal tea & & & & & & & & & \\
\hline Water & & & 0.731 & 0.309 & 0.462 & & & 0.330 & \\
\hline Alcoholic beverages & & & & & & & & -0.395 & \\
\hline Condiments and sauces & & & 0.365 & & 0.577 & & 0.432 & & \\
\hline Whole wheat cereal & & 0.829 & & & & 0.761 & & 0.612 & 0.468 \\
\hline Whole rye cereal & 0.512 & 0.407 & & 0.564 & & 0.497 & & & 0.603 \\
\hline Whole oat cereal & 0.926 & & & & & 0.665 & & 0.652 & \\
\hline Whole grain cereal, other & 0.906 & & & 0.613 & & & 0.682 & & \\
\hline Variation explained $(\%)$ & $9 \cdot 4$ & 8.0 & 7.9 & 11.4 & $10 \cdot 0$ & $8 \cdot 0$ & $8 \cdot 6$ & $7 \cdot 8$ & $7 \cdot 6$ \\
\hline
\end{tabular}

${ }^{*}$ Factor loadings below \pm 0.30 are not listed in the table. 


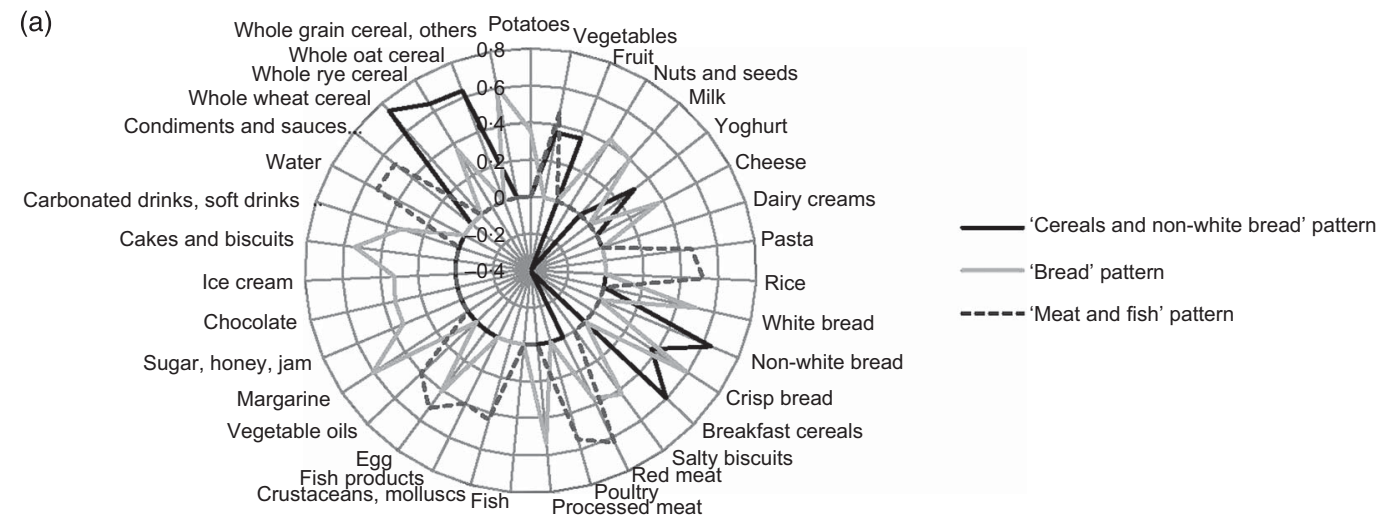

(b)
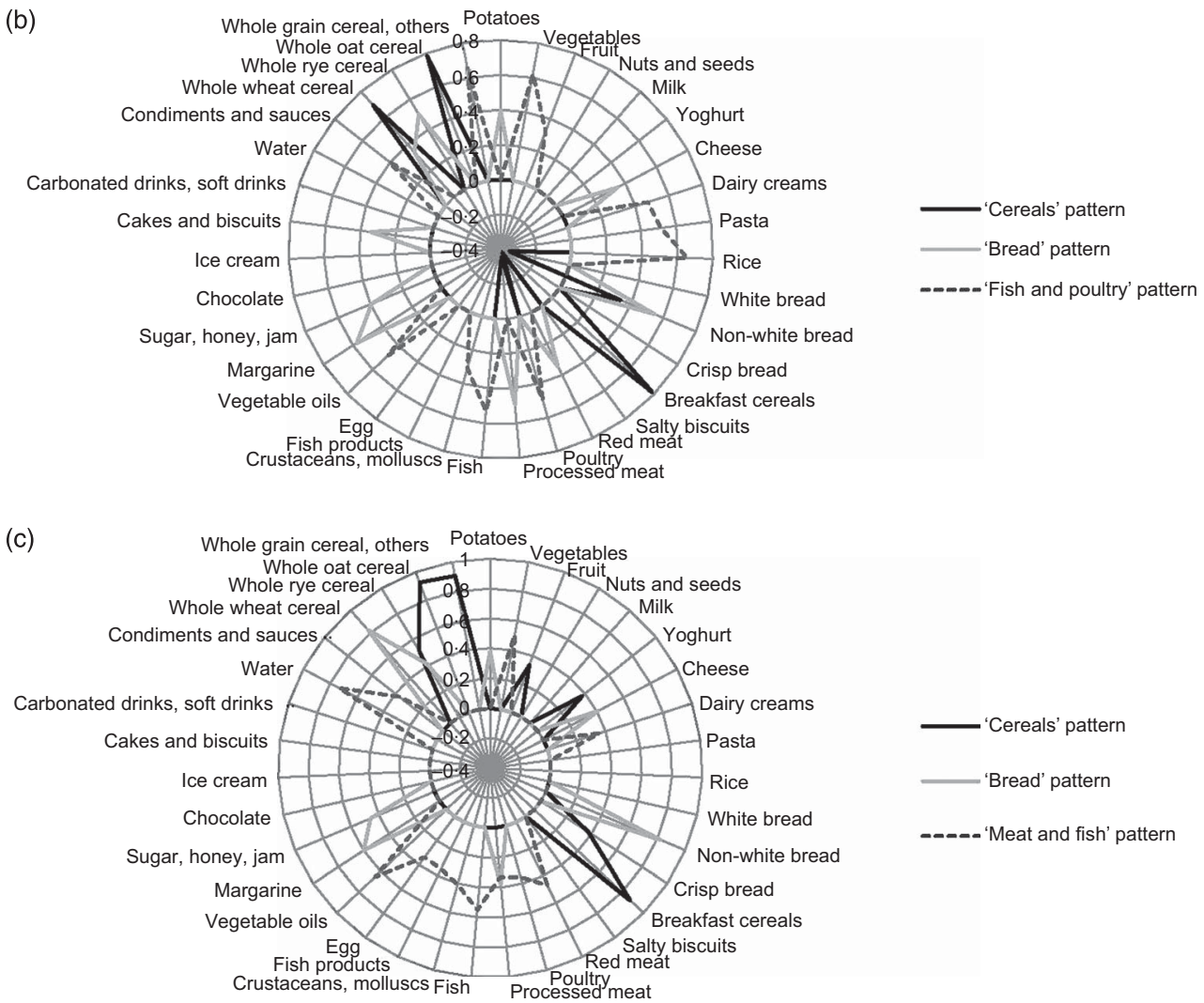

Fig. 1 Dietary patterns for Swedish (a), Danish (b) and Norwegian (c) women. The HELGA project

bread, margarine and rye as main items. The three factors explained $24 \%$ of the variation for men and $23 \%$ for women.

\section{Comparing the countries on gender}

The 'cereal' patterns for women (Fig. 1(a)-(c)) were quite similar in all three countries. However, looking at the whole grain contribution to the patterns, we found some differences. In Norway, this pattern had high loadings on rye, oat and other grains, while the Swedish 'cereal' pattern included non-white bread and loaded highest on wheat, rye and oat. Danish women had high loadings on wheat and oat in their cereal pattern.

The 'bread' patterns may be called 'traditional' patterns as they express the traditional way of consuming bread in
Scandinavia, with open sandwiches dressed with margarine, cheese, jam or meat/processed meat. A closer look at the food items in the 'traditional' bread patterns revealed big differences. In Norway and Denmark non-white bread appeared with the traditional sandwich dressings, while in Sweden white bread and crisp bread were found together with the sandwich dressings. In addition, the Swedish pattern included several sweet items: chocolate, cakes, ice cream and soft drinks. The whole grain items in these patterns were different too; in Norway wheat was the main item, Sweden scored highest on other whole grains and moderately high on rye, while Denmark scored highest on rye and moderately high on wheat.

The 'meat and fish' patterns were quite compatible for women in Norway and Sweden, but the Swedish pattern did 

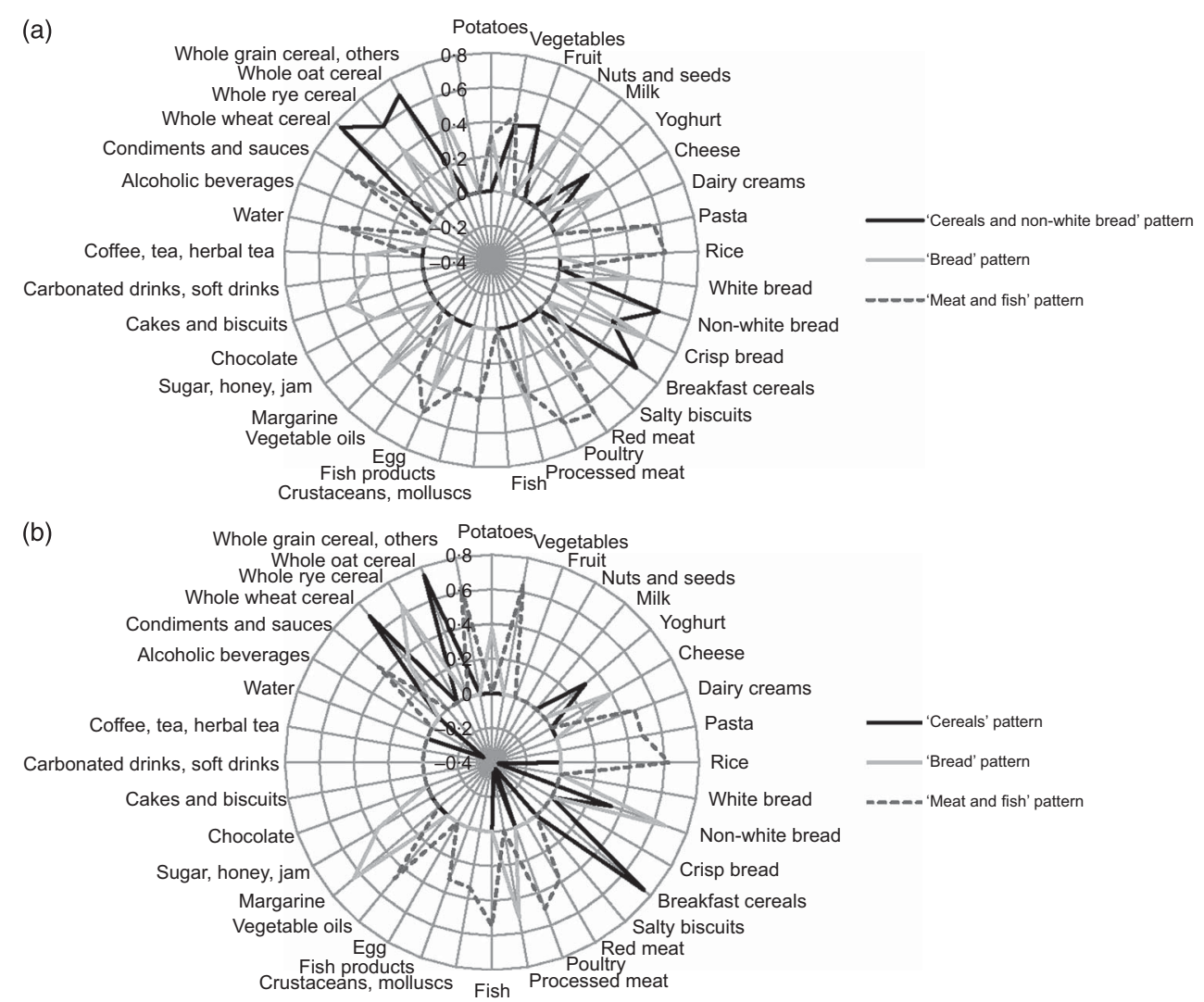

Fig. 2 Dietary patterns for Swedish (a) and Danish (b) men. The HELGA project

not include fish, only crustaceans and fish products. They also shared some similarities with the Danish women's 'poultry and fish' pattern. However, the Danish pattern did not include red and processed meat or fish products. None of the countries had patterns that were very similar to the patterns for females in the total cohort.

The patterns for men (Fig. 2(a) and (b)) were almost similar to what we saw for women in the respective countries, except that Danish women had a 'poultry and fish' pattern that did not include red meat and fish products as found in the 'meat and fish' pattern for Danish men. Thus, the differences between Swedish and Danish men were approximately the same as seen between Swedish and Danish women. Compared with the patterns for men in the total cohort, most similarities were seen in the Swedish patterns.

\section{Robustness of the patterns}

When dividing the data set randomly in two equal sized parts, both for the total cohort and in country-specific analyses, the same patterns appeared as in the main analyses, only with slightly different factor loadings.

\section{Discussion}

Our data indicate that even though we find similar dietary patterns in the Scandinavian countries, the food items representing the patterns reflect slightly different food cultures. Hence, one should be careful when treating the Scandinavian or Nordic countries as one.

Our results are in accordance with a previous study of Mäkelä et al. that found differences between meal patterns in the Nordic countries, with most similarities between Norway and Denmark, and between Sweden and Finland ${ }^{(31)}$. It also supports to some extent results shown in country-specific studies $^{(4-8)}$. A traditional pattern found by factor analysis in The Oslo Health Study ${ }^{(5)}$ corresponds to a fish pattern we found when we tried out a four-factor solution for Norway, and it also corresponds to the 'traditional fish eaters' pattern formerly found in the present Norwegian cohort $^{(7)}$. The Norwegian cohort was previously used for pattern analysis; however with a different approach and with different variables involved. The previous study revealed six different patterns, and two of the patterns were quite similar to two of the patterns found here; a 'healthy eater' pattern similar to our cereal pattern and a 'traditional bread eater' pattern similar to our traditional bread pattern.

Pattern analysis was previously performed on males in the present Danish cohort as well ${ }^{(32)}$. Both PCA and Treelet transform were used to explore the patterns, and seven different factors were found both in PCA and Treelet transform. When comparing the results from the PCA with our results, one factor is quite similar to our Danish 'bread' 
and one is close to our Danish 'meat' pattern. However, the choice of factors and the food group classification are different from our study; hence a direct comparison is not possible.

Additional analysis has not been performed on the entire Swedish cohort, but parts of the Västerbotten Intervention Programme constitute a part of the present Swedish cohort where Winkvist et al. ${ }^{(4)}$ reported patterns they assumed were more typical for Sweden. These patterns can to some extent correspond to the Swedish patterns we found, although it is difficult to compare the results since the analysis was done on a different cohort and different food items, and cluster analysis was performed, not PCA. The traditional pattern found by Wirfält et $a l^{(6)}$ in analysis of the Malmö Diet and Cancer study is quite similar to our Swedish bread pattern when comes to food items: white bread, sweets and soft drinks, but like for Winkvist et al. it is difficult to compare directly.

Patterns similar to our cereal pattern are found by several researchers; Hu et al. ${ }^{(33)}$ identified two different patterns by use of PCA in the Health Professionals Follow-up Study in the USA and named them 'prudent' and 'western'. The 'prudent' pattern had high scores on fruit and vegetables, fish, poultry and whole grains. Another American study by Hsiao et al. $^{(34)}$ identified, by means of cluster analysis, three patterns which they called 'western-like', 'low produce, high sweets' and 'more healthful'. The 'more healthful' pattern was characterised by high intakes of fruits, vegetables, whole grains, eggs, nuts, legumes and dairy products. A Greek study ${ }^{(35)}$ on healthy women identified ten patterns by the use of PCA, one of them a pattern with high scores on whole grain cereals and lowfat dairy. None of the studies has distinguished between different types of whole grains.

Our results confirm the results from a recent analysis of HELGA, based on data from 24 h dietary recalls ${ }^{(21)}$, where large differences in the type of whole grains used in Scandinavian countries were found; predominantly wheat in Norway, and rye in Sweden and Denmark.

The strength of the present study is the large sample size and the use of standardized data from validated questionnaires $^{(25-28)}$, in addition to the detailed information on intake of whole grains gained from the reclassification of the food variables.

FFQ are commonly known to have errors (inadequate food lists, inappropriate response categories, under- or over-reporting, etc.). The FFQ in the present study differ in design and are specific for each country, thus the details behind each food group included in the study may vary. This may be considered a limitation of the study.

There is an over-representation of persons with high socio-economic status in all three cohorts ${ }^{(36-38)}$, therefore the results may not be representative for the general population. Participants were recruited from all over Norway, but only from certain areas in Sweden and Denmark. However, participants were recruited from both rural and urban areas and may to some extent be considered to represent the entire countries, or regions ${ }^{(36-38)}$. Only the age groups represented in the current study can be considered; hence the findings do not reflect young people and in Norway they only reflect women.

The factors used in the analysis explained between $33 \%$ (total cohort) and $23 \%$ (Danish women) of the variation. This is the percentage of the variation that could be explained based on the criteria used to choose the number of factors; the rest is 'noise'. The factors cannot explain all the food choices of Scandinavian people, but represent those that can be identified and interpreted in the midst of the 'noise'. A higher number of factors would give a higher variation explained; however, the factors would give less meaning. The 'noise' only indicates that there are other dietary patterns than the ones mentioned here; but as explained in the Results section, they may be strongly overlapping the factors we have chosen.

The patterns were given approximately the same names in all three countries based on the food items characterising the patterns. However, a closer look at all the items included in each pattern revealed some differences between the countries and thus the names can be somewhat misleading. They were chosen based on the food items with the highest loadings in each pattern or most characteristic for the pattern (e.g. 'bread' pattern, because products with higher scores, like margarine, are associated with bread/sandwiches; or 'meat' pattern where vegetables, rice and pasta may have higher scores, but will be served with meat as the main dish). Therefore, patterns with the same names may include quite different food items, except for those representing the names. It is therefore important not to look only at the names, but to study patterns given the same names more closely. Factor analyses are encumbered with other subjective choices than the naming of patterns as well; the choice of how many factors to keep is another subjective choice to make. In our case we were most interested in whole grain items, and the factors were chosen based on what gives best information on whole grains.

Summing up, our data indicate that there are similar dietary patterns in the Scandinavian countries, however with differences reflecting different food cultures. The cereal pattern found in all three countries for both men and women, with high loadings on breakfast cereals and whole grain oat, may be considered a common Scandinavian whole grain pattern.

Food wise, the bread patterns seen for Norway and Denmark look quite similar. The Swedish bread pattern differs from the other two countries with white bread and crisp bread instead of non-white bread, and more sweet food items. However, the main whole grain in the Norwegian bread pattern is wheat, while it is rye in both Denmark and Sweden. The meat pattern for Danish women differs from the other meat patterns since it does not include red or processed meat, only poultry and fish. 
There are some gender differences in Denmark compared with Sweden, where men and women seem to share the same patterns.

Food items suggested to belong to a Nordic Food Index were found in three patterns for the total cohort and in Denmark, and in two patterns for Norway and Sweden.

The results from the current study are adding some information about food habits and patterns in Scandinavia and may be useful for Scandinavian health authorities when revising their food recommendations.

\section{Acknowledgements}

Financial support: This research was supported by NordForsk - Centre of Excellence Programme HELGA (070015). The funder had no role in the design, analysis or writing of this article. Conflict of interest: None. Authorship: All authors contributed with formulation and critical evaluation of the manuscript. D.H. also gave statistical advice. D.E. performed all statistical analyses and is the main author of the manuscript. Ethics of human subject participation: The study was conducted according to the guidelines laid down in the Declaration of Helsinki. All participants gave written informed consent, and the study was approved by the local ethical committees of the participating countries.

\section{Supplementary material}

To view supplementary material for this article, please visit http://dx.doi.org/10.1017/S1368980014001104

\section{References}

1. Cunha DB, Almeida RM \& Pereira RA (2010) A comparison of three statistical methods applied in the identification of eating patterns. Cad Saude Publica 26, 2138-2148.

2. Newby PK \& Tucker KL (2004) Empirically derived eating patterns using factor or cluster analysis: a review. Nutr Rev 62, 177-203.

3. Tucker KL (2010) Dietary patterns, approaches, and multicultural perspective. Appl Physiol Nutr Metab 35, 211-218.

4. Winkvist A, Hornell A, Hallmans G et al. (2009) More distinct food intake patterns among women than men in northern Sweden: a population-based survey. Nutr $J \mathbf{8}, 12$.

5. Kjollesdal MR, Holmboe-Ottesen G \& Wandel M (2011) Frequent use of staff canteens is associated with unhealthy dietary habits and obesity in a Norwegian adult population. Public Health Nutr 14, 133-141.

6. Wirfalt E, Mattisson I, Gullberg B et al. (2000) Food patterns defined by cluster analysis and their utility as dietary exposure variables: a report from the Malmo Diet and Cancer Study. Public Health Nutr 3, 159-173.

7. Engeset D, Alsaker E, Ciampi A et al. (2005) Dietary patterns and lifestyle factors in the Norwegian EPIC cohort: the Norwegian Women and Cancer (NOWAC) study. Eur J Clin Nutr 59, 675-684.

8. Lau C, Glumer C, Toft U et al. (2008) Identification and reproducibility of dietary patterns in a Danish cohort: the Inter99 study. Br J Nutr 99, 1089-1098.
9. Slimani N, Fahey M, Welch AA et al. (2002) Diversity of dietary patterns observed in the European Prospective Investigation into Cancer and Nutrition (EPIC) project. Public Health Nutr 5, 1311-1328.

10. Bonaccio M, Di Castelnuovo A, Bonanni A et al. (2013) Adherence to a Mediterranean diet is associated with a better health-related quality of life: a possible role of high dietary antioxidant content. BMJ Open 3, e003003.

11. Esposito K, Kastorini CM, Panagiotakos DB et al. (2013) Mediterranean diet and metabolic syndrome: an updated systematic review. Rev Endocr Metab Disord 14, 255-263.

12. Lopez-Garcia E, Rodriguez-Artalejo F, Li TY et al. (2014) The Mediterranean-style diet pattern and mortality among men and women with cardiovascular disease. Am J Clin Nutr 99 , $172-180$.

13. Lourida I, Soni M, Thompson-Coon J et al. (2013) Mediterranean diet, cognitive function, and dementia: a systematic review. Epidemiology 24, 479-489.

14. Singh B, Parsaik AK, Mielke MM et al. (2013) Association of Mediterranean diet with mild cognitive impairment and Alzheimer's disease: a systematic review and meta-analysis. J Alzheimers Dis 39, 271-282.

15. Adamsson V, Reumark A, Cederholm T et al. (2012) What is a healthy Nordic diet? Foods and nutrients in the NORDIET study. Food Nutr Res 2012, 56.

16. Kyro C, Skeie G, Loft S et al. (2013) Adherence to a healthy Nordic food index is associated with a lower incidence of colorectal cancer in women: the Diet, Cancer and Health cohort study. Br J Nutr 109, 920-927.

17. Olsen A, Egeberg R, Halkjaer J et al. (2011) Healthy aspects of the Nordic diet are related to lower total mortality. J Nutr 141, 639-644.

18. Akesson A, Andersen LF, Kristjansdottir AG et al. (2013) Health effects associated with foods characteristic of the Nordic diet: a systematic literature review. Food Nutr Res 2013, 57.

19. Aune D, Chan DS, Lau R et al. (2011) Dietary fibre, whole grains, and risk of colorectal cancer: systematic review and dose-response meta-analysis of prospective studies. BMJ 343, d6617.

20. Ye EQ, Chacko SA, Chou EL et al. (2012) Greater wholegrain intake is associated with lower risk of type 2 diabetes, cardiovascular disease, and weight gain. J Nutr 142, 1304-1313.

21. Kyro C, Skeie G, Dragsted LO et al. (2012) Intake of whole grain in Scandinavia: intake, sources and compliance with new national recommendations. Scand J Public Health 40, 76-84.

22. Fødevarestyrelsen (The Danish Veterinary and Food Administration) (2013) De 8 kostråd (The eight recommendations on nutrition). http://www.altomkost.dk/Anbefalinger/ De_officielle_kostraad/Kostraad.htm (accessed July 2013).

23. Helsedirektoratet (The Norwegian Directorate on Health) (2014) Kostholdsråd (Dietary recommendations). http:// helsedirektoratet.no/publikasjoner/anbefalinger-om-kostholdernering-og-fysisk-aktivitet/Sider/default.aspx (accessed February 2014).

24. Livsmedelverket (The Swedish Food Administration) (2013) Kostråd vuxna (Dietary recommendations - adults). http://www.slv.se/sv/grupp1/Mat-och-naring/Kostrad/Vuxna/ (accessed November 2013).

25. Hjartaker A, Andersen LF \& Lund E (2007) Comparison of diet measures from a food-frequency questionnaire with measures from repeated 24-hour dietary recalls. The Norwegian Women and Cancer Study. Public Health Nutr 10, 1094-1103.

26. Johansson I, Hallmans G, Wikman A et al. (2002) Validation and calibration of food-frequency questionnaire measurements in the Northern Sweden Health and Disease cohort. Public Health Nutr 5, 487-496. 
27. Overvad K, Tjonneland A, Haraldsdottir J et al. (1991) Development of a semiquantitative food frequency questionnaire to assess food, energy and nutrient intake in Denmark. Int J Epidemiol 20, 900-905.

28. Parr CL, Veierod MB, Laake P et al. (2006) Test-retest reproducibility of a food frequency questionnaire (FFQ) and estimated effects on disease risk in the Norwegian Women and Cancer Study (NOWAC). Nutr J 5, 4.

29. Slimani N, Kaaks R, Ferrari P et al. (2002) European Prospective Investigation into Cancer and Nutrition (EPIC) calibration study: rationale, design and population characteristics. Public Health Nutr 5, 1125-1145.

30. Edefonti V, Randi G, La VC et al. (2009) Dietary patterns and breast cancer: a review with focus on methodological issues. Nutr Rev 67, 297-314.

31. Makela J, Kjaernes U, Pipping EM et al. (1999) Nordic meals: methodological notes on a comparative survey. Appetite $\mathbf{3 2}$, 73-79.

32. Gorst-Rasmussen A, Dahm CC, Dethlefsen C et al. (2011) Exploring dietary patterns by using the treelet transform. $\mathrm{Am}$ J Epidemiol 173, 1097-1104.

33. Hu FB, Rimm EB, Stampfer MJ et al. (2000) Prospective study of major dietary patterns and risk of coronary heart disease in men. Am J Clin Nutr 72, 912-921.
34. Hsiao PY, Mitchell DC, Coffman DL et al. (2013) Dietary patterns and diet quality among diverse older adults: the University of Alabama at Birmingham Study of Aging. J Nutr Health Aging 17, 19-25.

35. Yannakoulia M, Yiannakouris N, Melistas L et al. (2008) A dietary pattern characterized by high consumption of whole-grain cereals and low-fat dairy products and low consumption of refined cereals is positively associated with plasma adiponectin levels in healthy women. Metabolism 57, 824-830.

36. Lund E, Kumle M, Braaten T et al. (2003) External validity in a population-based national prospective study - the Norwegian Women and Cancer Study (NOWAC). Cancer Causes Control 14, 1001-1008.

37. Tjonneland A, Olsen A, Boll K et al. (2007) Study design, exposure variables, and socioeconomic determinants of participation in Diet, Cancer and Health: a population-based prospective cohort study of 57,053 men and women in Denmark. Scand J Public Health 35, 432-441.

38. Weinehall L, Hallgren CG, Westman G et al. (1998) Reduction of selection bias in primary prevention of cardiovascular disease through involvement of primary health care. Scand J Prim Health Care 16, 171-176. 